\title{
Modeling and Analysis of Progressive Tool with Pilot Location
}

\author{
S.Chandra Sekhar ${ }^{1}$,Sk.Surjan ${ }^{2}$,T.D.Rama Krishna ${ }^{3}$ \\ ${ }^{1}$ Assistant Professor Department of Mechanical Engg. Sri Vasavi Engineering College, Pedatadepalli, \\ Tadepalligudem \\ ${ }^{2}$ Assistant Professor Department of Mechanical Engg. Sri Vasavi Engineering College ,Pedatadepalli, \\ Tadepalligudem \\ ${ }^{3}$ Assistant Professor Department of BSH, Sri Vasavi Engineering College, Pedatadepalli, Tadepalligudem
}

\begin{abstract}
Press tool components play an important role in every aspects of modern word. There are different types of press tools are available, in this progressive tools are more influence the automobile industry for mass production. The operation of a progressive die involves the series of sheet metal operations at two or more stations during each press stroke for developing the complete work piece. The strip must move from the first station through each succeeding station and perform one or more distinct die operations at each working station. One or more idle stations may be incorporated in the die. In this paper we use software CATIA V5 for modeling a progressive tool to manufacture a washer for M12 bolt. In earlier design there is no primary stopper for first station and there are no accurate location like pilots for further station. In this design we provide primary stopper for first station, pilots for further stations and also we replace the die block with die buttons. For this any damage occurs on die button simply we can replace that particular die button instead of replacement of entire die block this will reduce the material cost, machining time and die maintenance.
\end{abstract}

A. Sheet metal shearing operations

\section{INTRODUCTION}

While there are many die-cutting operations, some of which are very complex, they can all be reduced to the following simple fundamentals.

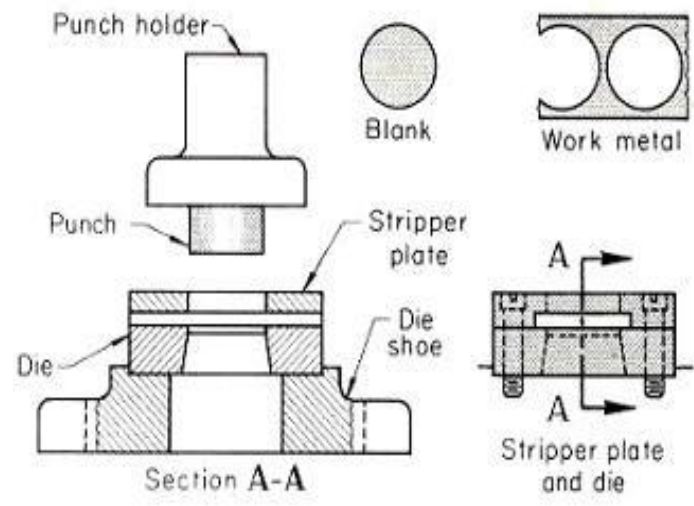

Fig: 1 Drop-through Blanking Die

\section{B. Plain blanking}

Fig.1 shows a simple operation of this type. The material used is called the stock and is generally a ferrous or nonferrous strip. During the working stroke the punch goes through the material, and on the return stroke the material is lifted with the punch

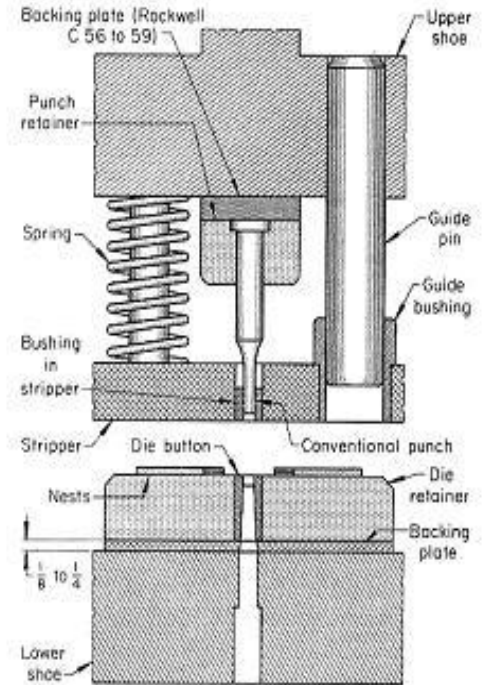

Fig: 2 Piercing Die Assembly

and is removed by the stripper plate. The stop pin is a gage for the operator. In practice, he feeds the stock by hand and locates the holes to be punched as shown. The part that is removed from the strip is always the work piece (blank) in a blanking operation. 


\section{Piercing}

This operation consists of simple hole punching. It differs from blanking in that the punching (or material cut from stock) is the scrap and the strip is the work piece. Piercing is nearly always accompanied by a blanking operation before, after, or at the same time. Fig. 4-2 shows a typical piercing die assembly.

\section{CUTTING ACTION IN PUNCH AND DIE OPERATIONS}

The cutting action that occurs in blanking or piercing is quite similar to that of chip formation ahead of a cutting tool. The punch contacts the work material supported by the die and a pressure buildup occurs. When the elastic limit of the work material is exceeded, the material begins to flow plastically (plastic deformation). The punch penetrates the work material, and the blank, or slug, is displaced into the die opening a corresponding amount. A radius is formed on the top edge of the hole and the bottom edge of the slug, or blank, as shown in Fig: 3. The radius is often referred to as rollover and its magnitude depends upon the ductility of the work material. Compression of the slug material against the walls of the die opening burnishes a portion of the edge of the blank, as shown in Fig. 4-11b. At the same time, the plastic flow pulls the material around the punch, causing a corresponding burnished area in the work material. Further continuation of the punching pressure then starts fractures at the cutting edge of the punch and dies as shown in Fig: 3.

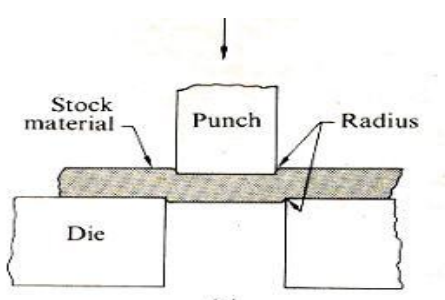

(a)
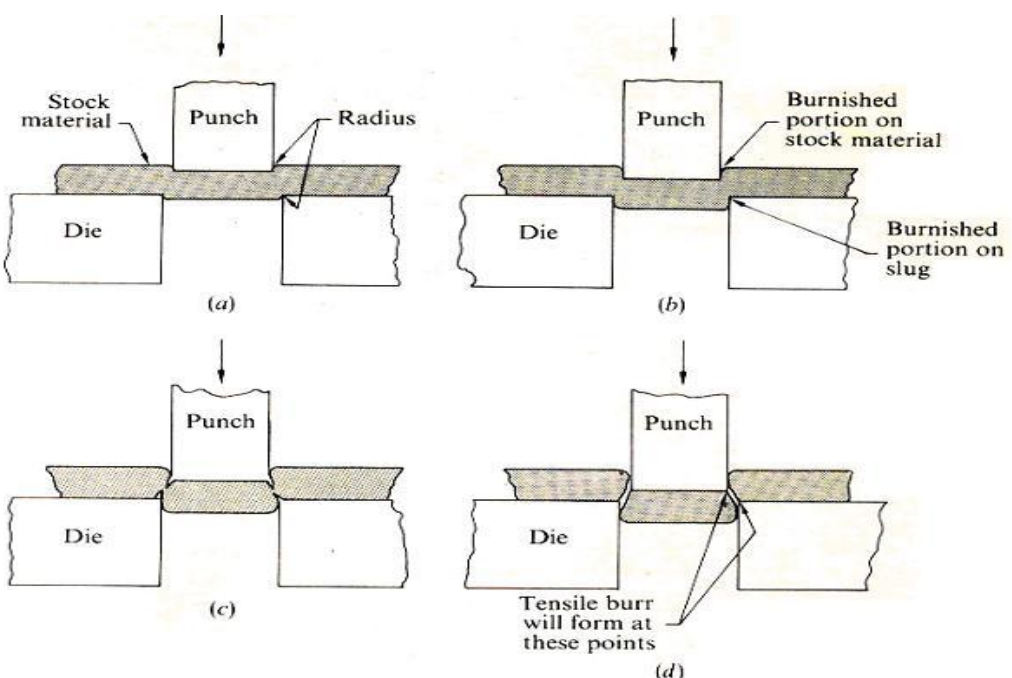

(c)

(d)

Fig: 3 Cutting action progression when blanking and piercing metal

\section{A. Die Clearance}

Clearance is defined as the intentional space between the punch cutting edge and die cutting edge. Clearance is always expressed as the amount of clearance per side. Theoretically, clearance is necessary to allow the fractures to meet when break Occurs, the amount of clearance depends upon the kind, thickness and hardness of the work material. Excessive clearance allows a large edge radius (rollover) and excessive plastic deformation. The edges of the material tend to be drawn or pulled in the direction of the working force, and the break is not smooth. Large burrs are present at the break edge. Insufficient cutting clearance caused the fractures to miss and prevents a clean break, a partial break occurs, and a secondary break connects the original or main fractures. This is often referred to as secondary shear. The secondary break does not allow separation of the material without interference, and a second burnished ring is formed. The burnished ring may appear as a slight step around the outside edge of the blank or around the inside edge of the hole. Insufficient clearance increase pressure on the punch and dies edge and has a marked effect on die life.

\section{B. Press tonnage:}

The tonnage of a press is the force that the press ram is able to exert safely. Press slides exert forces greater than the rated tonnage because of the built-in safety factor, but this is not a license to overload. The tonnage of hydraulic presses is the piston area multiplied by the oil pressure in the cylinder. Changing the oil pressure varies the tonnage. The tonnage of mechanical presses is determined by the size of the bearings for the crankshaft or eccentric and is approximately equal to the shear strength of the crankshaft metal multiplied by the area of the crankshaft bearings. The tonnage of a mechanical press is always given when the slide is near the bottom of its stroke because it is greatest at this point. 


\section{Shut height:}

The shut height of a press is the distance from the top of the bed to the bottom of the slide with the stroke down and the adjustment up. The thickness of the bolster plate must always be taken into consideration when determining the maximum die height. The shut height of the die must be equal to or less than the shut height of the press. The shut height of a press is always given with the adjustment up. Lowering the adjustment of the slide may decrease the opening of the press from the shut height down, but it does not increase the shut height. Thus the shut height of a die must not be greater than the shut height of the press. It may be less, because lowering the adjustment can reduce the die opening in the press.

\section{PROCEDURE FOR PROGRESSIVE DIE DESIGN}

\section{A. Die placement}

Make sure that the die is set so that the material feeds parallel to the tool. Parallel feed can be achieved several ways, such as stop pins, keyways, and conical locaters. Only one type of locater is necessary. Avoid "sighting in" the tool as this process is difficult to repeat and inaccurate. When possible, try to place the center of the estimated tonnage in the center of the press and not the centerline of the die in the center of the bolster.

\section{B. Pitch and progression}

Make sure the feed pitch and progression are set correctly. Overfeeding or underfeeding most likely will result in a misfeed and die damage.

\section{Material thickness, type, mechanical properties}

Verify the metal thickness, and, when possible, verify that it is the right type to be used in the die.

\section{Scrap ejection}

Make sure that all slug belts and shakers are in place and functioning properly.

\section{E. Shut height}

Ensure that the shut height of the die is set correctly. Avoid using press counters to establish the finish shut height. Avoid hitting setup blocks. Because a press defects, it may be necessary to calibrate the finished shut height after the die is fully loaded.

\section{F. First-hit line}

This is a very important step and requires careful attention. Starting the material in the wrong spot can cause half-hits of half-forms. Unbalanced cutting or forming can cause the upper and lower dies to misalign and shear. Also, incorrectly starting the material can leave loose scrap in the die. If the scrap is not removed, double metal results and is fed into the tool. This condition can cause severe die damage. A good die designer establishes a distinct first-hit line by placing a positive spring-loaded stop at this point, rather than a simple line with a message: Start strip here.

\section{G. Bolts and fasteners}

Double-check all of the bolts securing the die in the press, making sure that they are tightened and secure. Make no assumptions. Despite the fact that this seems obvious, it still helps to have a checklist reminder.

\section{H. Counterbalance}

Make sure the press counterbalance pressure is set properly with respect to the upper-die weight. Not doing so can cause poor ram-to-bolster parallelism, unnecessary press loading, as well as excessive wear, die shearing, a tonnage loss, and a press energy loss.

\section{Slug ejection}

Make sure that the scrap falls off the tool freely during all operations, including cutting and piercing.

Table I: Materials for press tools

\begin{tabular}{|c|c|c|c|}
\hline $\begin{array}{l}\text { Positio } \\
n\end{array}$ & Part Description & Material & $H R c$ \\
\hline 1 & Die shoes & $\begin{array}{l}\text { Cast iron or } \\
\text { M. S. / En } 8\end{array}$ & \\
\hline 2 & $\begin{array}{l}\text { Die housing, Punch holder- } \\
\text { Stripperplate,spacerplates, } \\
\text { Shank and Strip support. }\end{array}$ & M. S. or En 8 & \\
\hline 3 & $\begin{array}{l}\text { All guide pillar and bush. } \\
\text { Spring loaded stripper guide } \\
\text { Pin and bushes. } \\
\text { Floating die guide pin And bushes. }\end{array}$ & $\begin{array}{l}\text { Case hardening } \\
\text { Steel - En } 36 \text { or Equivalent. } \\
\text { O1 }\end{array}$ & $\begin{array}{l}\text { Case } 54-58 \\
\text { Core } 38-42 \\
54-58\end{array}$ \\
\hline 4 & $\begin{array}{l}\text { Stripper insert, Guide plates, stopper pin, pilot } \\
\text { punches }\end{array}$ & OHNS (O1) / W1 / W2 & $54-58$ \\
\hline 5 & $\begin{array}{l}\text { Cutting Die and Punches. } \\
\text { Coining, Bending, forming } \\
\text { Die buttons and Punches. }\end{array}$ & $\begin{array}{l}\mathrm{D} 2 \text { / D3 / D4 / } \\
\mathrm{M} 2 \text { / Carbide } \\
\mathrm{O} 1 \text { / A2 / D2 }\end{array}$ & $\begin{array}{ll}58-62 & 160 \\
64 & \\
86-90 & \\
56-60 & \\
\end{array}$ \\
\hline
\end{tabular}


A2 air-hardening medium-alloy $(5 \% \mathrm{Cr})$ tool steel

D2, D3, D4 high-carbon high-chromium airhardening tool steel

M2 high speed steel is the least costly, most used, and most readily available high-speed steel

O1 Oil-hardening steel

\section{FORCE CALCULATIONS}

\section{A. Shear force}

The force required to be exerted by the punch in order to shear out the blank from the stock can be estimated from the actual shear area and shear strength of the material using formulae,

$\mathrm{F}_{\mathrm{sh}}=\left(\mathrm{KLtS}_{\mathrm{sh}}\right) \mathrm{kgs}$

Where $\mathrm{K}=1.1$ to 1.5 (normal clearance)

$$
=1.25 \text { to } 1.75 \text { when } \mathrm{d} / \mathrm{t}<2
$$

$\mathrm{L}=$ Length of cut in $\mathrm{mm}$

$\mathrm{t}=$ thickness of stock in $\mathrm{mm}$

$$
\begin{aligned}
& \quad \begin{array}{c}
\mathrm{S}_{\mathrm{sh}}=\text { shear strength of the material } \\
\left(\mathrm{kg} / \mathrm{mm}^{2}\right)
\end{array} \\
& =36 \mathrm{~kg} / \mathrm{mm}^{2} \\
& \therefore \mathrm{F}_{\mathrm{sh}}=1.1 \times 116.1 \times 1 \times 36 \\
& =4597.56 \mathrm{~kg}
\end{aligned}
$$

\section{B. Stripping force}

Stripping force is require to remove the strip from the punch after the cutting operation. It is given as $5 \%$ of Total shear force.

Stripping force is the force, which controls the metal flow .It is the force applied by the blank holder on the blank to control the flow of the metal in to the die cavity. Important consideration in tooling for sheet metal forming wrinkling of sheet as it is being formed. Hold down can best be provided by hold down ring. However by using mechanical spring or an auxiliary air cylinder, hold down can be provided in a single action press.

$$
\begin{aligned}
\mathrm{F}_{\mathrm{st}} & =(0.05-0.08) \mathrm{F}_{\mathrm{sh}} \text { for normal clearance } \\
& =(0.1-0.2) \mathrm{F}_{\mathrm{sh}} \text { for narrow clearance } \\
\mathrm{F}_{\mathrm{st}} & =0.05 \times 4597.56 \\
& =229.87 \mathrm{~kg}
\end{aligned}
$$

$$
\begin{aligned}
& \text { C. Ejection force } \\
& \begin{aligned}
\mathrm{F}_{\text {ej }} & =0.1 \times \mathrm{F}_{\text {sh }} \\
& =0.1 \times 4597.56 \\
& =459.756 \mathrm{~kg}
\end{aligned}
\end{aligned}
$$

D. Thickness of plates

$$
\text { Thickness of die plate } \begin{aligned}
\left(\mathrm{t}_{\mathrm{d}}\right) & =\sqrt[3]{\mathrm{F}_{\text {sh }}} \\
& =\sqrt[3]{ }(4597.56) \\
& =16.62 \mathrm{~mm}
\end{aligned}
$$

Thickness of bottom bolster $=1.75 \mathrm{t}_{\mathrm{d}}$

$$
=1.75 \times 16.62
$$$$
=29.1 \mathrm{~mm}
$$

Thickness of top bolster $\quad=1.25 \mathrm{t}_{\mathrm{d}}$

$$
\begin{aligned}
& =1.25 \times 16.62 \\
& =20.775 \mathrm{~mm} \\
\text { Thickness of stripper plate } & =0.5 \mathrm{t}_{\mathrm{d}} \\
& =0.5 \times 16.62 \\
& =8.32 \mathrm{~mm} \\
\text { Tool cutting load } & =\mathrm{F}_{\mathrm{sh}}+\mathrm{F}_{\mathrm{st}} \\
& =4597.56+229.87 \\
& =4827.43 \mathrm{kgs} \\
& =4827.43 \times 9.81 \\
& =47357 \mathrm{~N} \cong \mathbf{5 0 0 0 0} \mathbf{~}
\end{aligned}
$$

\section{MODELING OF PRESS TOOL}

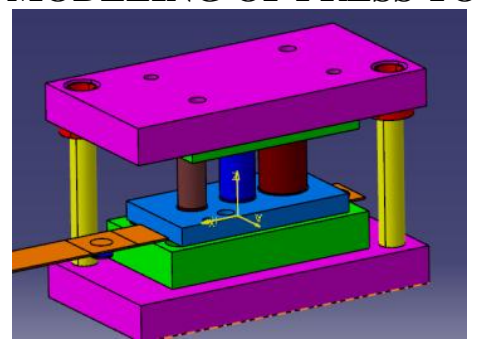

Fig: 4 Total assembly of the press tool

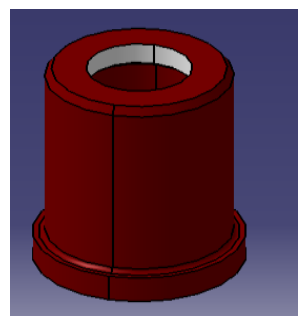

Fig: 5 Die button -1

Fig 5 shows the designed part of die button insert for blanking operation

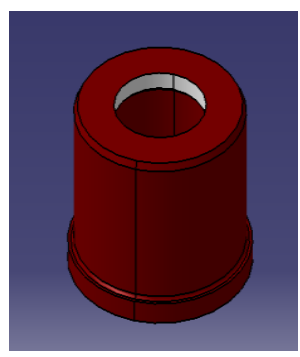

Fig: 6 Die button -2

Fig 6 shows the designed part of die button insert for piercing operation

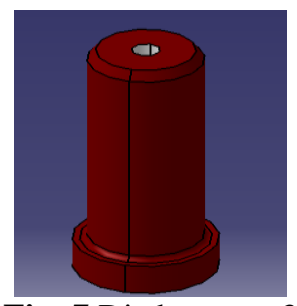

Fig: 7 Die button -3

Fig 7 shows the designed part of die button insert for pilot locating hole operation 


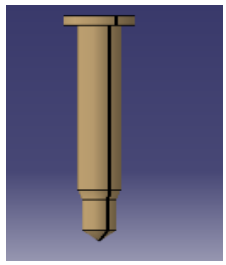

Fig: 8 Pilot

Fig 8 shows the designed part of pilot for accurate location in the die for equal pitch

\section{THEORETICAL DEFLECTION AND STRESS CALCULATION}

\section{A. Die block}

Assuming that the die block (die plate) is considered to be as fixed beam. The shoe deflection is calculation using the strength of material formula for fixed supported beam.

$\therefore$ Deflection $\delta=\mathrm{FL}^{3} / 192 \mathrm{EI}$

Where $\mathrm{F}=80 \%$ of cutting force $=0.8 \times 50000$

$$
\mathrm{L}=104 \mathrm{~mm}, \mathrm{E}=2 \times 10^{5} \mathrm{~N} / \mathrm{mm}^{2}
$$$$
=40000 \mathrm{~N}
$$$$
\mathrm{I}=\mathrm{bh}^{3} / 12=4.6 \times 10^{4} \mathrm{~mm}^{4}
$$

Where $b=70 \mathrm{~mm}, \mathrm{~h}=20 \mathrm{~mm}$

$$
\begin{aligned}
\therefore \delta & =\left(40000 \times 104^{3}\right) /\left(192 \times 2 \times 10^{5} \times 4.6 \times 10^{4}\right) \\
& =2.8 \times 10^{-2} \mathrm{~mm}
\end{aligned}
$$

$$
\text { Stress } \begin{aligned}
\mathrm{p} & =\mathrm{F} / \mathrm{A} \\
& =40000 /(70 \times 20) \\
& =132 \times 10^{6} \mathrm{~Pa}
\end{aligned}
$$

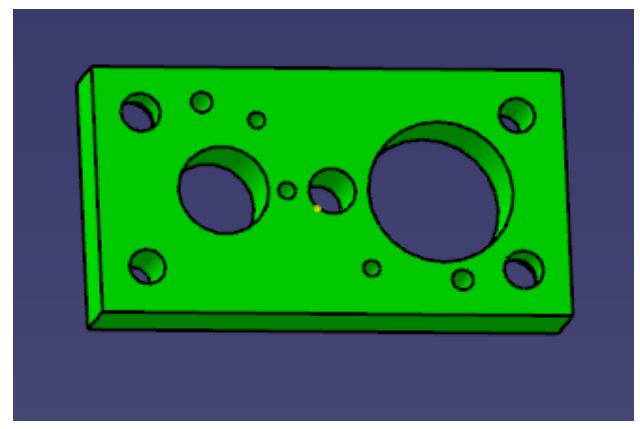

Fig: 9 Die block of the press tool

\section{B. Top plate}

Top plate indicates as for calculation and analysis purpose as top plate, punch back plate and punch plate, assuming that the top plate is considered to be on parallels. The shoe deflection is calculated using the strength of material formula.

Deflection $\delta=\mathrm{FL}^{3} / 48 \mathrm{EI}$

Where $\mathrm{F}=80 \%$ of cutting force $=0.8 \times 47357$ $=40000 \mathrm{~N}$

$$
\mathrm{L}=160 \mathrm{~mm}, \mathrm{E}=2.1 \times 10^{5} \mathrm{~N} / \mathrm{mm}^{2}
$$

$\mathrm{I}=\mathrm{bh}^{3} / 12=6.6 \times 10^{4} \mathrm{~mm}^{4}$

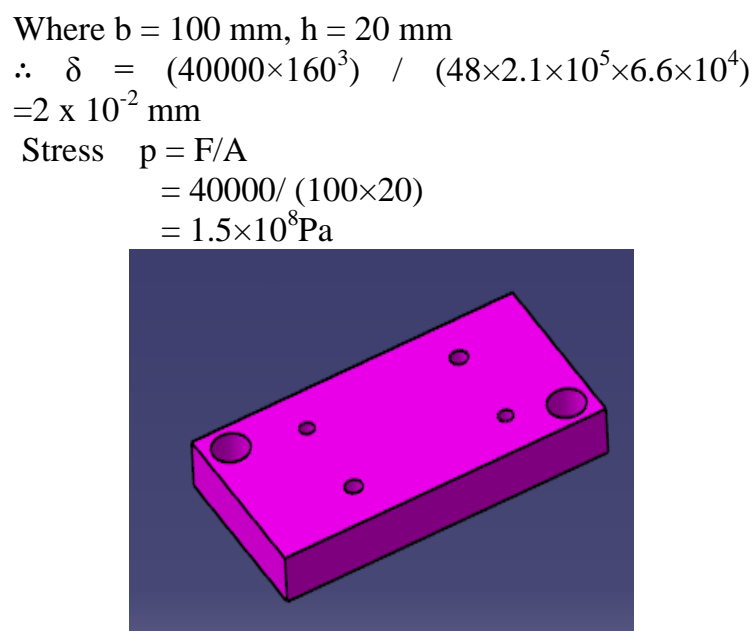

\section{Bottom plate}

Fig: 10 Top plate of the press tool

Assuming that the bottom plate is considered to be on parallels. The shoe deflection is using the strength of material formula for parallels supported beam.

$$
\begin{aligned}
& \text { Deflection } \delta=\mathrm{FL}^{3} / 354 \mathrm{EI} \\
& \text { Where } \mathrm{F}=80 \% \text { of cutting force }=37885.67 \mathrm{~N} \\
& \mathrm{~L}=190 \mathrm{~mm}, \mathrm{E}=2.1 \times 10^{5} \mathrm{~N} / \mathrm{mm}^{2} \\
& \mathrm{I}=\mathrm{bh}^{3} / 12=6.6 \times 10^{4} \mathrm{~mm}^{4} \\
& \text { Where } \mathrm{b}=100 \mathrm{~mm}, \mathrm{~h}=20 \mathrm{~mm} \\
& \therefore \delta=\left(40000 \times 190^{3}\right) /\left(354 \times 2.1 \times 10^{5} \times 6.6 \times 10^{4}\right) \\
& \text { Stress } \mathrm{p}=\mathrm{F} / \mathrm{A} \\
& =1.185 \times 10^{-2} \mathrm{~mm} \\
& =40000 /(100 \times 20) \\
& =2 \times 10^{8} \mathrm{~Pa}
\end{aligned}
$$

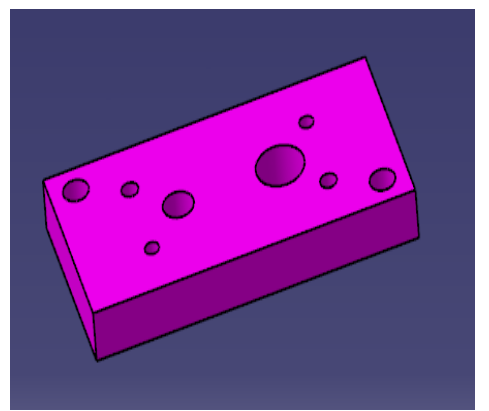

Fig: 11 Bottom plate of the press tool

\section{Stripper plate}

Assuming fixed stripper to be considered as a fixed beam support. The fixed stripper plate deflection and stress is calculated using the strength of material formula.

Deflection $\delta=$ FL/192EI

Where $\mathrm{F}=10 \%$ to $20 \%$ of cutting force $=0.1 \times 47357$ $\mathrm{N}$

$\mathrm{N}$

$$
\mathrm{L}=110 \mathrm{~mm}, \mathrm{E}=2.1 \times 10^{5} \mathrm{~N} / \mathrm{mm}^{2}
$$




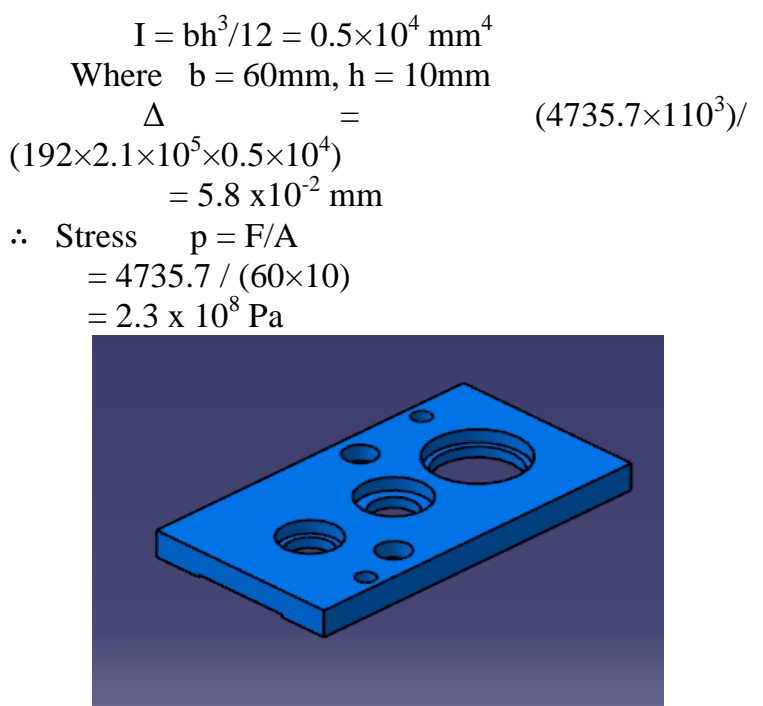

Fig: 12 Stripper plate of the press tool

\section{E. Guide pillar}

The diameter of guide pillar is $=1.1$ to $1.3 \times$ thickness of die plate

$$
=1.1 \times 20=22 \mathrm{~mm}>15 \mathrm{~mm} \text {. }
$$

$\therefore$ Hence the guide pillars diameter is safe dimension. Assuming that the guide pillars as a cantilever beam vertical load. So guide pillar is as consider as a one side is fixed and other end is free column construction, From strength of materials for column construction of one end is fixed and other end is free type , clipping load as $\mathrm{P}=\pi^{2} \mathrm{EI} / 4 \mathrm{~L}^{2}$

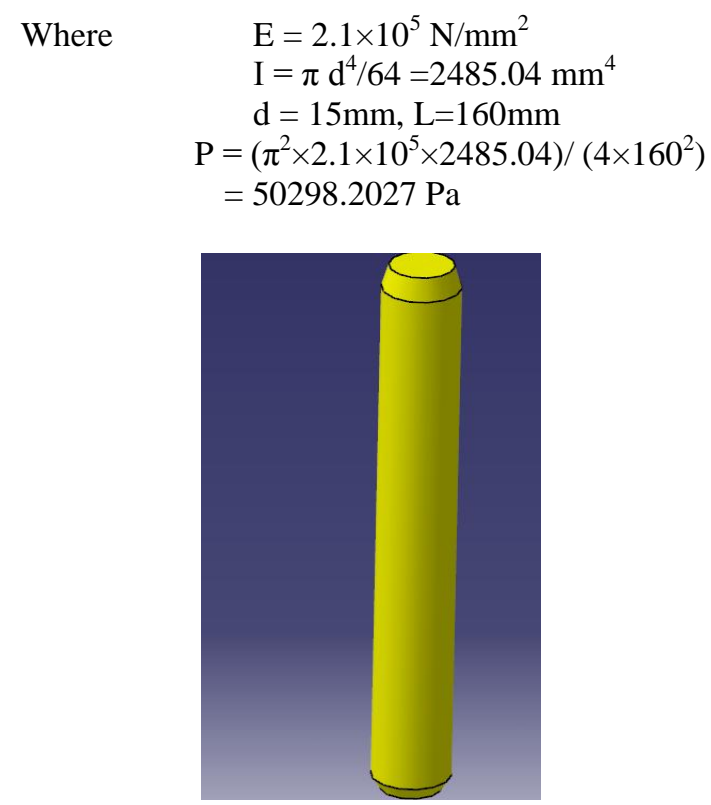

Fig: 13 Guide Piller of the press tool

\section{ANALYSIS OF PROGRASSIVE DIE}

The analysis of the progressive die is done in the ANSYS software. This gives the comparison between analytic and numerical value. Part is drawn in CATIA V5 software and these parts are imported to ANSYS software in (.igs) format.

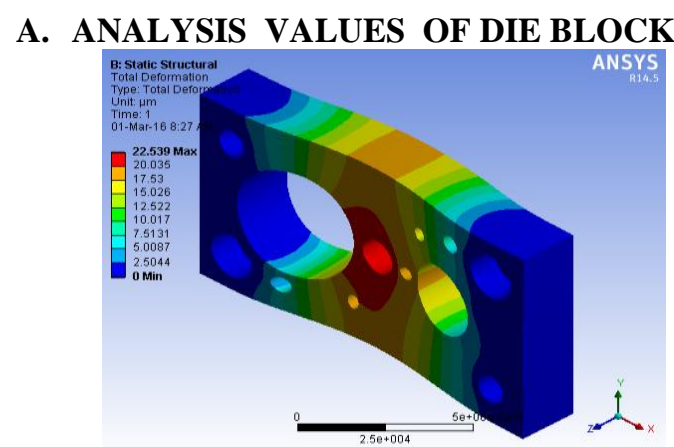

Fig: 14 Total deformation in die block

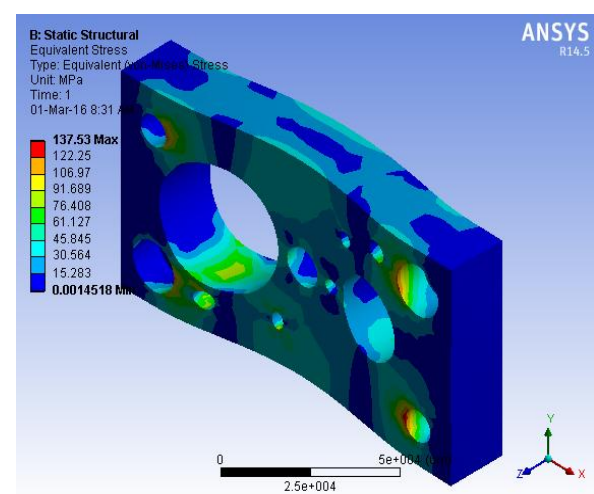

Fig: 15 Equivalent stress in die block

Fig 14 and Fig 15 are the obtained results of the die block which is analyzed in ansys software. Fig 14 shows the deformation results of the die block and fig 15 shows the results of equivalent stress in die block

\section{B. ANALYSIS VALUES OF TOP PLATE :}

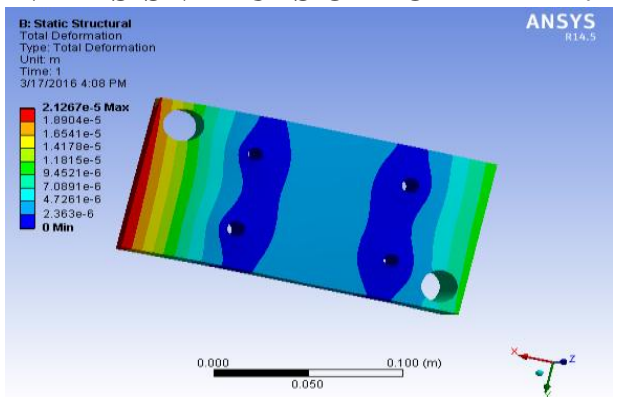

Fig: 16 Total deformation in top plate 


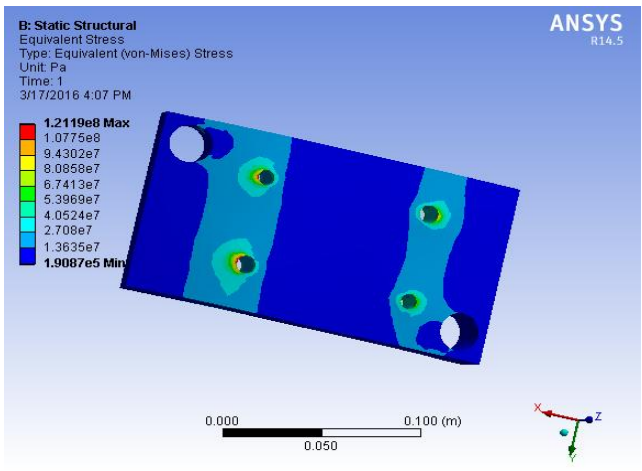

Fig: 17 Equivalent stress in top plate

Fig 16 and Fig 17 are the obtained results of the top plate which is analyzed in ansys software. Fig 16 shows the deformation results of the top plate and fig 17 shows the results of equivalent stress in top plate

\section{ANALYSIS VALUES OF BOTTOM PLATE}

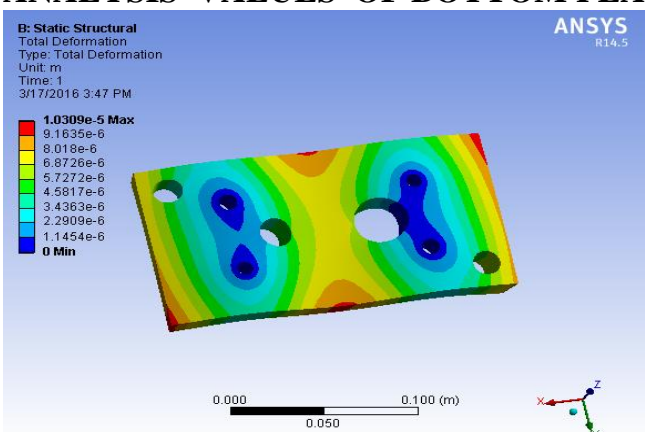

Fig: 18 Total deformation in bottom plate

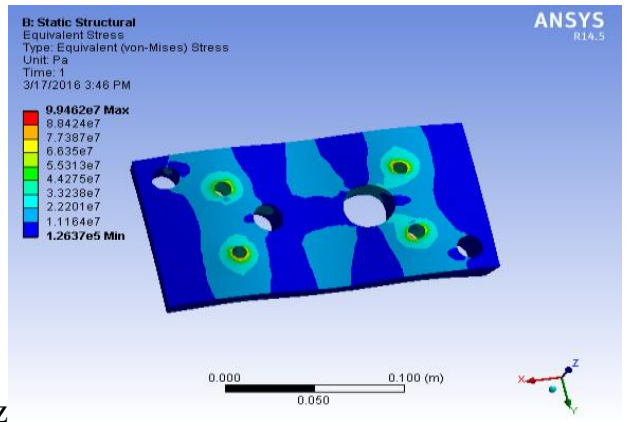

Fig: 19 Equivalent stress in bottom plate
Fig 18 and Fig 19 are the obtained results of the bottom plate which is analyzed in ansys software. Fig 18 shows the deformation results of the bottom plate and fig 19 shows the results of equivalent stress in bottom plate.

\section{ANALYSIS VALUES OF STRIPPER PLATE}

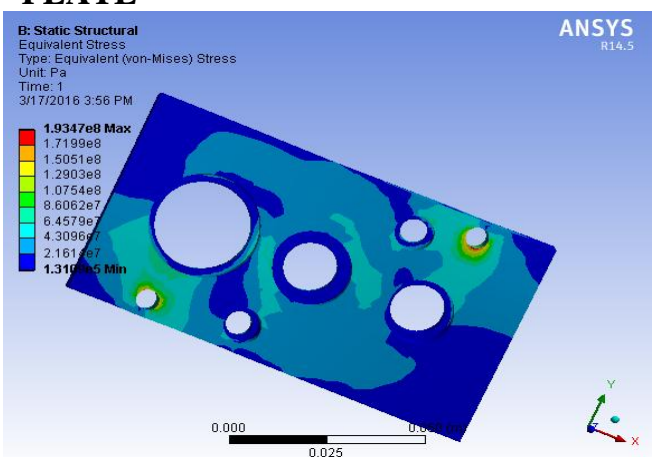

Fig: 20 Equivalent stress in stripper plate

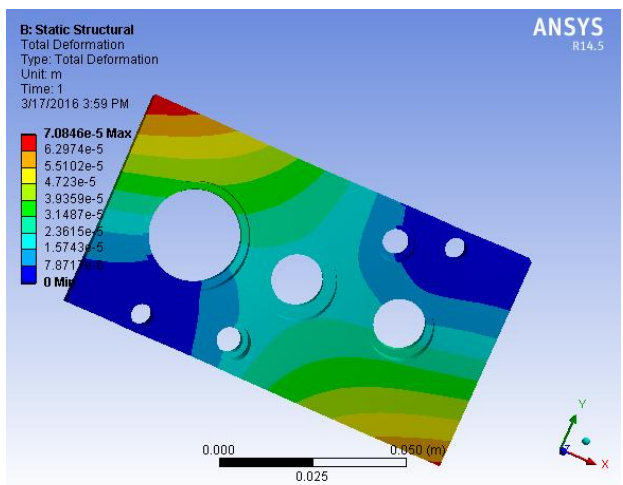

Fig: 21 Total deformation in stripper plate

Fig 20 and Fig 21 are the obtained results of the stripper plate which is analyzed in ansys software. Fig 21shows the deformation results of the stripper plate and fig 20 shows the results of equivalent stress in stripper plate.

Table II: Analysis Result

\begin{tabular}{|c|c|c|c|c|c|c|}
\hline S.No & Description & Thickness & \multicolumn{2}{|c|}{ Calculated result } & \multicolumn{2}{|c|}{ Analysis result } \\
\cline { 4 - 6 } & & $(\mathbf{m m})$ & $\begin{array}{c}\text { Deflection } \\
(\mathbf{m m})\end{array}$ & $\begin{array}{c}\text { Stress } \\
(\mathbf{p a})\end{array}$ & $\begin{array}{c}\text { Deflection } \\
(\mathbf{m m})\end{array}$ & $\begin{array}{c}\text { Stress } \\
(\mathbf{p a})\end{array}$ \\
\hline 1 & Die block & 15 & $2.8 \times 10^{-2}$ & $132 \times 10^{6}$ & 2.2 \\
& & 30 & $1.1 \times 10^{-2}$ & $137.5 \times 10^{6}$ \\
\hline 2 & Bottom plate & $2 \times 10^{8}$ & $1.038 \times 10^{-2}$ & $9.946 \times 10^{7}$ \\
\hline 3 & Top plate & 20 & $2 \times 10^{-2}$ & $1.5 \times 10^{8}$ & $2.127 \times 10^{-2}$ & $1.211 \times 10^{8}$ \\
\hline 4 & Stripper plate & 10 & $5.8 \times 10^{-2}$ & $2.3 \times 10^{8}$ & $7.084 \times 10^{-2}$ & $1.934 \times 10^{8}$ \\
\hline
\end{tabular}




\section{CONCULSION}

Progressive die is an economical way to form metal part with suitable of characteristic including strength, ductility, and wear resistance. This research deals with the two stage progressive die has been designed for the washer manufacturing. Compound die is also used for manufacturing this washer but its design is more complicated and economically high expensive.

The individual components of progressive tool were modeled in CATIA V5. Each individual file was imported in ANSYS 14.5 software through initial graphics exchange specification (IGES) format. The following conclusions were made.

1) The results obtained through analysis are approximately nearer to the theoretical values. This demonstrates that the analysis carried out was correct .It's also observed that the design of progressive tool is safe as all the stress values were less than the allowable stress of the material.

2) The modeling of a progressive tool is done on the Catia V5 software and is imported to ansys software for analysis.

3) In this design primary stopper and pilots are incorporated for accurate location of the sheet in the progressive tool

4) In this design D2 die buttons are placed in a En-8 Die block instead of D2 Die block. If any damage occurs to the die button we will replace the die buttons instead of whole die block which will reduce the material cost and machining cost.

\section{REFERENCES}

[1]. [1] Tool Engineering Parameters CITD.

[2]. DESIGN OF PROGRESSIVE DIES International Journal of Engineering Research and Applications (IJERA) ISSN: 2248-9622 www.ijera.com Vol. 2, Issue 3, May-Jun 2012, pp.2971-2978.

[3]. Design and Analysis of Progressive Tool International Journal of Engineering Research \& Technology (IJERT) Vol. 1 Issue 6, August 2012 ISSN: 2278-0181

[4]. Dieter, G., Engineering Design, McGraw-Hill International Editions, Mechanical Engineering Series, ISBN0-07-366136-8, USA 2000 4. Paquin, J.R. \& Crowley, R.E., Die design

[5]. Progressive Die Wizard Help, EDS 2003

[6]. H. S. Ismail, S. T. Chen and K. K. B. Hon. 'Feature-Based Design of Progressive Press Tools.'InternationalJournal of Machine Tools and Manufacture, Vol. 36, Issue3, pp. 367378, 1996.
[7]. Industrial steel reference book by $\mathrm{SN}$ Bagachi, Kuldipprakash

[8]. Seon-Bong Lee, Dong-Hwan Kim, ByungMin Kim. 'Development of optimal layout design system in multihole blanking process.' Journal of Materials Processing Technology 130-131 20 December 2002, Pages 2-8

[9]. Sung-Bo Sim, Sung-Taeg Lee, Chan-Ho Jang. 'A study on the development of center carrier type progressive dies for U-bending part process.' Journal of Materials Processing Technology, Volumes 153-154, November 2004, Pages 1005-1010. 